\title{
Conformational analysis and comparison between theoretical and experimental vibration spectra for isocyanate species on $\mathrm{Ag} / \mathrm{Al}_{2} \mathrm{O}_{3}$ catalyst
}

\author{
Hongwei Gao, Hong He*
}

Research Center for Eco-Environmental Sciences, Chinese Academy of Sciences, 18 Shuangqing Road, Haidian District, Beijing 100085, China

Received 28 December 2003; accepted 24 June 2004

\begin{abstract}
Density functional theory (DFT) calculations were performed to study the structure and vibrational frequencies of the intermediate for the isocyanate (NCO) surface species on $\mathrm{Ag} / \mathrm{Al}_{2} \mathrm{O}_{3}$ catalyst using the GAUSSIAN 98 suite of programs. Thermal decomposition of adsorbed $\mathrm{CH}_{3} \mathrm{NO}_{2}$ species leads to the formation of two types of $\mathrm{NCO}$ species ( $\mathrm{NCO}$ on Ag and $\mathrm{NCO}$ on $\mathrm{Al}_{2} \mathrm{O}_{3}$ ) above $298 \mathrm{~K}$. In order to investigate the reaction mechanism, we have designed the calculated models $(\mathrm{a}-\mathrm{g})$ for the NCO intermediate. Through the analysis of the vibration mode and the vibration frequency of the calculated models $(\mathrm{a}-\mathrm{g})$, we conclude that there is an excellent agreement between the calculated vibration spectrum of the model (e) containing the $-\mathrm{Ag}-\mathrm{NCO}$ group or model ( $\mathrm{g}$ ) containing the $-\mathrm{Al}-\mathrm{NCO}$ group and the experimental vibration spectrum.
\end{abstract}

(C) 2004 Elsevier B.V. All rights reserved.

Keywords: DFT; Structure; NCO intermediate; Vibrational spectrum; DRIFTS

\section{Introduction}

Simulating infrared spectra with ab initio, semi-empirical and density functional theory (DFT) methods are at present widely used in many fields. The simultaneous coupling of gas chromatography with Fourier transform IR spectroscopy (FTIR) and mass spectrometry (MS) detectors is currently one of the most powerful tools for the separation and unambiguous identification of complex mixtures of organic compounds. An especially important and intriguing case is the analysis of unknown compounds. During the past years, several papers have been published exemplifying how IR simulations can assist identification of organic compounds by means of the coupled technique of gas chromatography-Fourier transform IR spectroscopy-mass spectrometry (GC-FT-IR-MS) [1-4].

The selective catalytic reduction of NO by hydrocarbons (HC-SCR of NO) is a potential method of controlling the emissions from stationary and mobile resources in which the engine operates in oxygen-rich conditions (e.g. diesel and

\footnotetext{
* Corresponding author. Tel.: +86 10 62849123; fax: +86 1062849123 .

E-mail address: honghe@mail.rcess.ac.cn (H. He).
}

lean-burn engines) [5-8]. The mechanism of HC-SCR of NO in the presence of excess oxygen over $\mathrm{Ag} / \mathrm{Al}_{2} \mathrm{O}_{3}$ has been proposed as [9-16]

$$
\begin{gathered}
\mathrm{NO}+\mathrm{O}_{2}+\mathrm{C}_{3} \mathrm{H}_{6} \rightarrow \mathrm{C}_{x} \mathrm{H}_{y} \mathrm{NO}_{z} \\
\rightarrow \mathrm{NCO}(\mathrm{a}) \stackrel{\mathrm{NO}, \mathrm{O}_{2}}{\longrightarrow} \mathrm{N}_{2}+\mathrm{CO}_{2}
\end{gathered}
$$

and [13]

$$
\begin{aligned}
& \mathrm{NO}+\mathrm{O}_{2}+\mathrm{C}_{2} \mathrm{H}_{5} \mathrm{OH} \rightarrow \mathrm{H}_{2} \mathrm{C}=\mathrm{CH}-\mathrm{O}-\mathrm{M}+\mathrm{NO}_{x} \\
& \rightarrow \mathrm{NCO}(\mathrm{a}) \stackrel{\mathrm{NO}_{2} \mathrm{O}_{2}}{\longrightarrow} \mathrm{N}_{2}+\mathrm{CO}_{2}
\end{aligned}
$$

Based on our previous IR study [10,13], NCO species were detected on the $\mathrm{Ag} / \mathrm{Al}_{2} \mathrm{O}_{3}$ surface in a vacuum system for the reaction $\mathrm{NO}+\mathrm{O}_{2}+\mathrm{C}_{3} \mathrm{H}_{6}$ (or $\mathrm{C}_{2} \mathrm{H}_{5} \mathrm{OH}$ ). Because of facile formation of $\mathrm{C}_{x} \mathrm{H}_{y} \mathrm{NO}_{z}$ and high reactivity of $\mathrm{NCO}$ species in the presence of $\mathrm{NO}$ and $\mathrm{O}_{2}$, we concluded that the $\mathrm{NCO}$ species on the $\mathrm{Ag} / \mathrm{Al}_{2} \mathrm{O}_{3}$ surface were the crucial intermediates of the reactions (1) and (2).

The reactivity of the intermediates containing the isocyanate group $-\mathrm{N}=\mathrm{C}=\mathrm{O}$ in catalytic chemistry has attracted 


$$
\mathrm{Ag}-\mathrm{N}=\mathrm{C}=\mathrm{O}
$$

(a)<smiles></smiles>

(d)

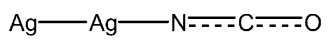

(b)

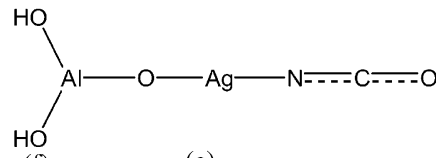

(e)

(f)
$\mathrm{Ag}-\mathrm{O}-\mathrm{Ag}-\mathrm{N}=\mathrm{C}=\mathrm{C}=\mathrm{O}$

(c)

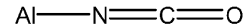

(g)<smiles>O=C=N[AlH2]</smiles>

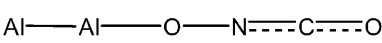<smiles></smiles>

(j) (h) (i)

Fig. 1. Calculational models for the reaction of $\mathrm{NCO}$ species on $\mathrm{Ag} / \mathrm{Al}_{2} \mathrm{O}_{3}$ catalyst.

investigations of their conformations, structure and vibrational spectra. Although the reaction mechanism on $\mathrm{Ag} / \mathrm{Al}_{2} \mathrm{O}_{3}$ catalyst has been investigated by some researchers, there is still a limited understanding about the fundamental role of intermediate and surface chemistry involved in the de $-\mathrm{NO}_{x}$ reaction. The exact structure of the intermediates formed by the $\mathrm{NCO}$ species on $\mathrm{Ag} / \mathrm{Al}_{2} \mathrm{O}_{3}$ catalyst for the selective catalytic reduction of de- $\mathrm{NO}_{x}$ is still not clear.

The objective of this work was to study the formation and surface structure of the $\mathrm{NCO}$ intermediates on $\mathrm{Ag} / \mathrm{Al}_{2} \mathrm{O}_{3}$ catalyst using experimental and theoretical methods for the reaction as follows:

$$
\mathrm{CH}_{3} \mathrm{NO}_{2} \rightarrow \mathrm{NCO}(\mathrm{a})
$$

Because of the unknown structure of the NCO intermediates on $\mathrm{Ag} / \mathrm{Al}_{2} \mathrm{O}_{3}$ surface, we have designed eleven calculational models (a-k) (see Fig. 1) to investigate the structure and the vibrational frequencies of the NCO intermediate for reaction (3). The main goal of this work was to compare general views of simulated IR spectra for these calculational models with experimental spectra. A fundamental understanding of the reaction mechanism of the $\mathrm{SCR}$ of $\mathrm{NO}_{x}$ is believed to be essential for the development of a catalyst and improvement for its potential application.

\section{Theoretical}

The GAUSSIAN 98 program [17] running on an OPTIPLEX (TM) GX260SD with Interl (R) Pentium (R) 4, 2.26 GHz Processor and 512 MB RAM was used to optimize the structures and calculate the vibrational wavenumbers for the $\mathrm{NCO}$ intermediate on $\mathrm{Ag} / \mathrm{Al}_{2} \mathrm{O}_{3}$ catalyst. The $3-21 \mathrm{G}^{*}$

Table 1

\begin{tabular}{|c|c|c|c|c|c|c|c|}
\hline Model & $r(\mathrm{~N}=\mathrm{C})$ & $R(\mathrm{C}=\mathrm{O})$ & $R(\mathrm{~N}-\mathrm{M})$ & $\mathrm{N}-\mathrm{C}-\mathrm{O}$ & $\mathrm{M}-\mathrm{N}-\mathrm{C}$ & $\mathrm{Va}(\mathrm{NCO})$ & Intensity \\
\hline $\mathrm{a}$ & 1.20 & 1.21 & 2.03 & 179.88 & 178.90 & 2333 & 920 \\
\hline b & 1.21 & 1.20 & 2.25 & 179.97 & 138.31 & 2264 & 857 \\
\hline $\mathrm{c}$ & 1.20 & 1.21 & 2.04 & 179.98 & 179.84 & 2321 & 1103 \\
\hline $\mathrm{d}$ & 1.20 & 1.21 & 2.02 & 179.96 & 179.85 & 2308 & 1500 \\
\hline $\mathrm{e}$ & 1.21 & 1.21 & 2.02 & 179.75 & 177.52 & 2215 & 967 \\
\hline Experimental & $1.23[15]$ & $1.146[15]$ & & 180.00 [15] & & 2212 & \\
\hline f & 1.21 & 1.19 & 1.80 & 179.96 & 179.20 & 2336 & 1152 \\
\hline g & 1.23 & 1.18 & 2.02 & 180.00 & 137.88 & 2267 & 1228 \\
\hline $\mathrm{h}$ & 1.21 & 1.19 & 1.78 & 179.95 & 179.82 & 2347 & 1989 \\
\hline I & 1.21 & 1.19 & 1.78 & 179.76 & 175.48 & 2371 & 1262 \\
\hline j & 1.22 & 1.18 & 1.93 & 176.38 & 135.10 & 2318 & 747 \\
\hline $\mathrm{k}$ & 1.22 & 1.18 & 1.96 & 176.45 & 138.70 & 2317 & 887 \\
\hline Experimental & $1.23[18]$ & 1.15 [18] & & 180.00 [18] & & 2237 & \\
\hline
\end{tabular}

Geometrical parameter, calculated vibration frequencies and intensity of the NCO antisymmetric stretching mode for the calculational models (a-k)

The units for bond length, bond angle, vibration frequency and intensity are angstrom, degree, $\mathrm{cm}^{-1}$ and $\mathrm{km} \mathrm{mol}^{-1}, \mathrm{respectively} . \mathrm{M}=\mathrm{Ag}, \mathrm{Al}$. 


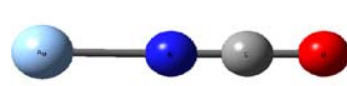

(a)

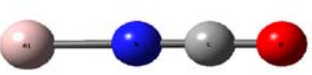

(f)
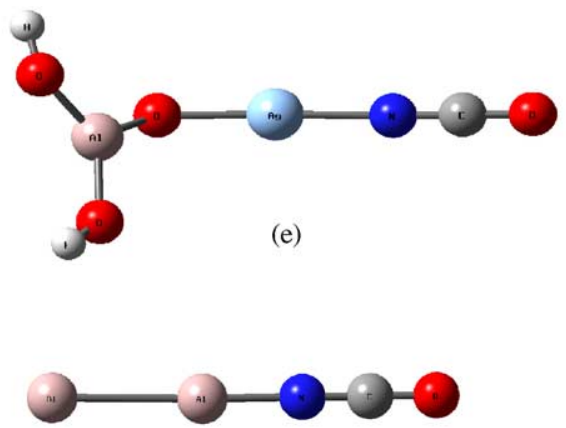

(h)

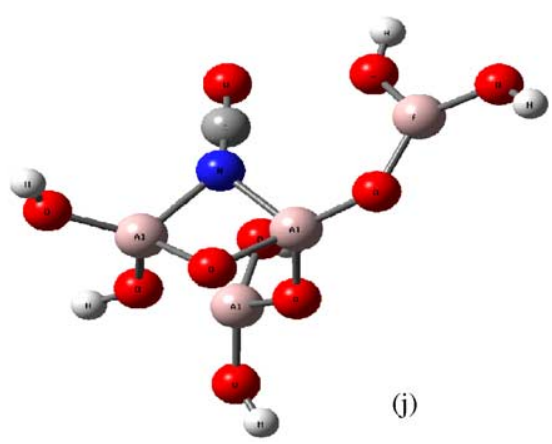

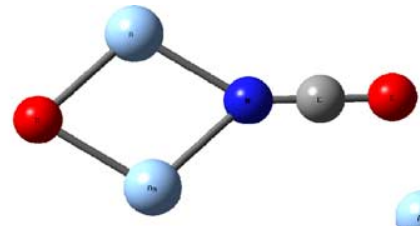

(b)

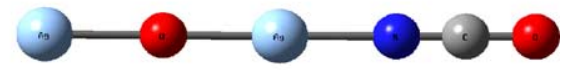

(d)
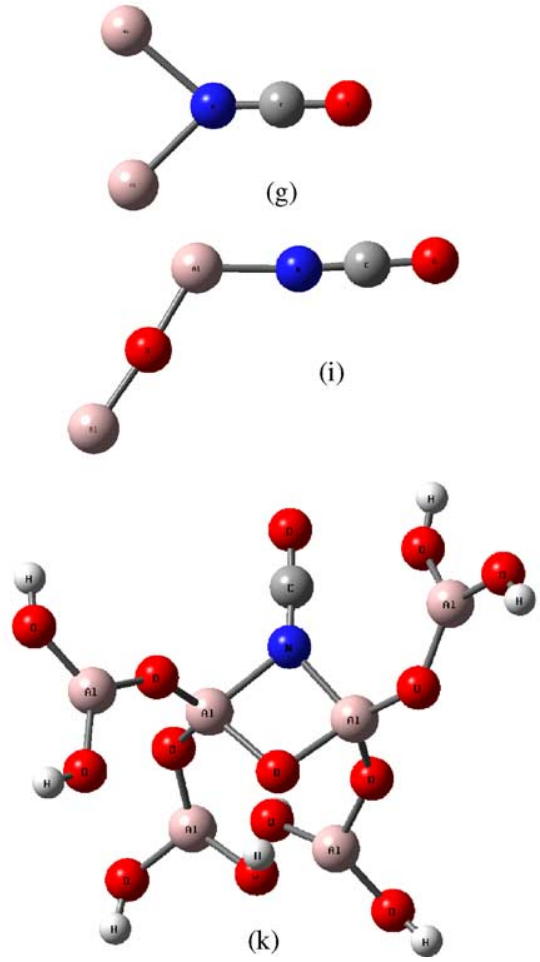

Fig. 2. The optimized structure of computational models for the adsorption of $\mathrm{NCO}$ with $\mathrm{Ag} / \mathrm{Al}_{2} \mathrm{O}_{3}$ cluster. Red circles: $\mathrm{O}$ atoms; black circles: $\mathrm{C}$ atoms; blue circles: $\mathrm{N}$ atoms; white circles: $\mathrm{H}$ atoms; gray circles: $\mathrm{Al}$ atoms; cyan circles: Ag atoms. (For interpretation of the references to colour in this figure legend, the reader is referred to the web version of the article.)

basis set was employed to carry out the DFT-B3PW91 (Becke's three parameter functional with the non-local correlation provided by the Perdew 91 expression) calculations. The resulting vibrational frequencies and intensities were read by the Hyperchem ${ }^{\mathrm{TM}}$ Version 6.0 package. We have analyzed the vibration spectrum using HyperChem program.

The HyperChem program offers many types of molecular and quantum mechanics calculations; however, the calculations for vibrational frequencies consume much time. From our experience, the calculations for a compound of more than 100 Da molecular weight normally take more than 3 days. The method in this paper combines both Gaussian 98 program and HyperChem program, thus saving a lot of computational time.

As a new quantum-chemical method, DFT has been exponentially used in inorganic and organo-metallic chemistry in the past few years with great success. Unlike the Hartree-Fock theory, DFT recovers electron correlation in the self-consistent Kohn-Sham procedure through the functions of electron density and gives good descriptions for systems, which require sophisticated treatments of electron correlation in the conventional ab initio approach. Hence, not only is it a cost effective method, but also it is a reliable one.

\section{Experimental}

An $\mathrm{Ag} / \mathrm{Al}_{2} \mathrm{O}_{3}$ catalyst (Ag loading is $5.0 \mathrm{wt} . \%$ ) was prepared by an impregnation method as described in our earlier paper [12]. In situ diffuse reflectance infrared Fourier transform spectroscopy (DRIFTS) spectra were recorded on a Nexus 670 (Thermo Nicolet) FT-IR, equipped with an in situ diffuse reflection chamber and a high sensitivity MCT detector. $\mathrm{An} \mathrm{Ag} / \mathrm{Al}_{2} \mathrm{O}_{3}$ catalyst (ca. $30 \mathrm{mg}$ ) for the in situ DRIFTS studies was finely ground and placed into a ceramic crucible in the chamber. Prior to recording each DRIFTS spectrum, the sample was heated in situ in $10 \% \mathrm{O}_{2} / \mathrm{He}$ flow at $873 \mathrm{~K}$ for $1 \mathrm{~h}$, then cooled to the desired temperature for taking a reference spectrum. At room temperature, $\mathrm{CH}_{3} \mathrm{NO}_{2}$ was introduced by $\mathrm{He}$ carrier. After $5 \mathrm{~min}$ adsorption of $\mathrm{CH}_{3} \mathrm{NO}_{2}$ on catalyst surface, all DRIFTS spectra were measured with a resolution of $4 \mathrm{~cm}^{-1}$ and with an accumulation of 100 scans in the flow of He gas. 


\section{Results and discussion}

\subsection{Optimized structure}

The models used in the calculation of the adsorption of $\mathrm{NCO}$ species on $\mathrm{Ag} / \mathrm{Al}_{2} \mathrm{O}_{3}$ catalyst are shown in Fig. $1(\mathrm{a}-\mathrm{k})$. The optimized structures of the calculational models are plotted in Fig. 2. The optimized geometrical parameters are listed in Table 1. From Table 1, the calculated value of the $\mathrm{N}=\mathrm{C}$ bond length in NCO for the models (a-k) is about $1.20-1.23 \AA$, which is within $1 \%$ of the experimental value of $1.23 \AA$. The $\mathrm{C}=\mathrm{O}$ bond length in NCO for models $(\mathrm{a}-\mathrm{k})$ determined from DFT calculations is $1.18-1.21 \AA$, and the corresponding literature value at MP2/6-31G* level is $1.173 \AA$ [15]. The optimized distance between the nitrogen atom and the aluminum atom in the models (a-e) is about 2.03-2.25 $\AA$, while the optimized bond length for the $\mathrm{N}-\mathrm{Al}$ bond in the models ( $\mathrm{f}-\mathrm{k})$ is about $1.80-2.02 \AA$. The calculated equilibrium

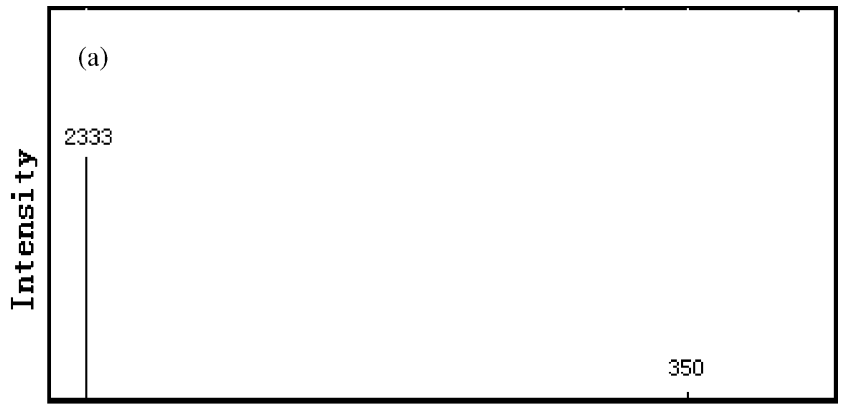

Tave Number $(1 / \mathrm{cm})$

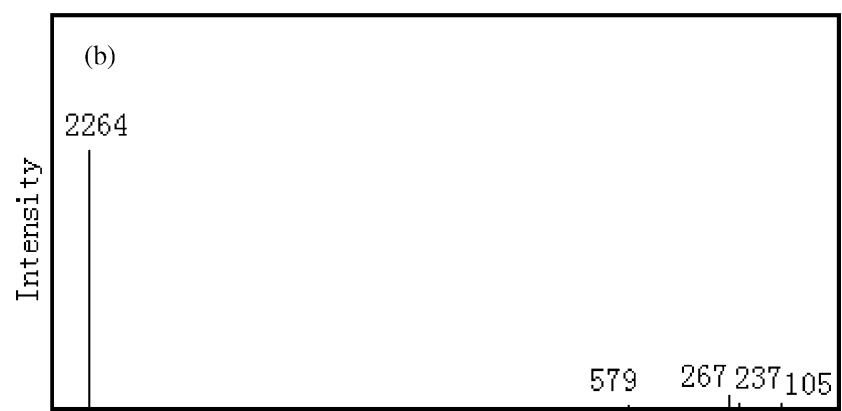

Wave Number $(1 / \mathrm{cm})$

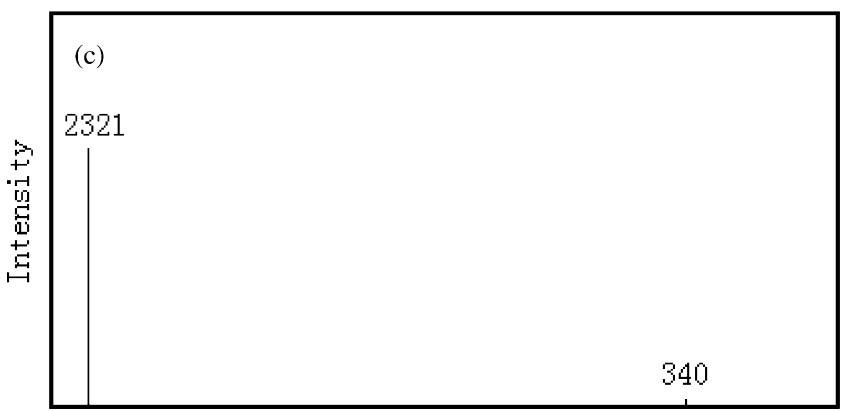

Wave Number $(1 / \mathrm{cm})$

Fig. 3. Calculated spectra of models a, b and c with the spectra simulated by the methods B3PW91. $\angle \mathrm{N}-\mathrm{C}-\mathrm{O}$ bond angle in NCO for the models $(\mathrm{a}-\mathrm{k})$ about $176.45-179.98^{\circ}$ is in agreement with the corresponding experimental value of $180^{\circ}$.

\subsection{Comparison of calculated and experimental spectra}

The calculated vibration frequencies and intensity of the NCO antisymmetric stretching mode for the calculational models $(\mathrm{a}-\mathrm{k})$ and experimental values are presented in Table 1.The calculated spectra of models $(\mathrm{a}-\mathrm{k})$ and experimental spectra are plotted in Figs. 3-7.

Fig. 7 shows the in situ DRIFT spectra of $\mathrm{Ag} / \mathrm{Al}_{2} \mathrm{O}_{3}$ in a flow of $\mathrm{He}$ at a temperature range of $298-673 \mathrm{~K}$ in steady states. Exposure of this catalyst to $\mathrm{CH}_{3} \mathrm{NO}_{2}$ at room temperature resulted in the appearance of two peaks (2237 and $2212 \mathrm{~cm}^{-1}$ ). Based on our theoretical calculation, the peak at $2237 \mathrm{~cm}^{-1}$ was assigned to $v_{\mathrm{as}}(\mathrm{NCO})$ on $\mathrm{Ag}$ atom surface and the peak of $2212 \mathrm{~cm}^{-1}$ was assigned to $\nu_{\mathrm{as}}(\mathrm{NCO})$ on $\mathrm{Al}$ atom surface. These NCO species are thermally stable
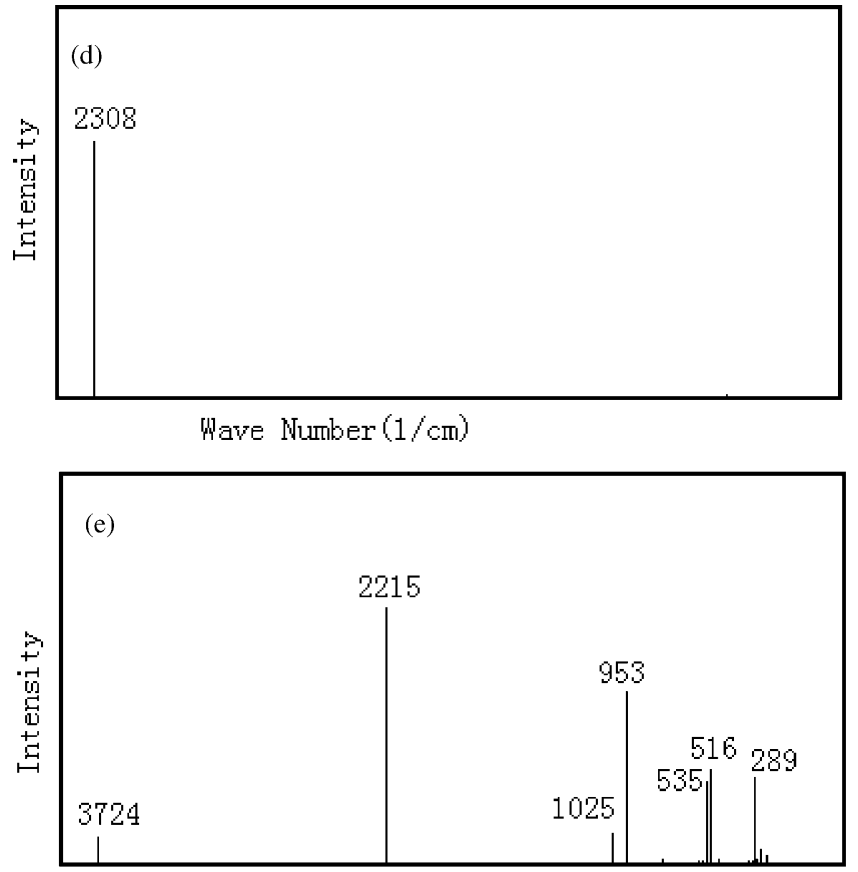

Wave Number $(1 / \mathrm{cm})$

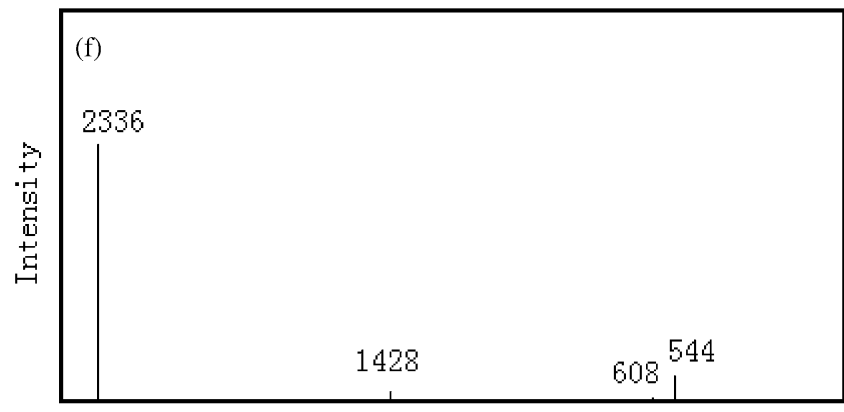

Wave Number $(1 / \mathrm{cm})$

Fig. 4. Calculated spectra of models $\mathrm{d}$, e and $\mathrm{f}$ with the spectra simulated by the methods B3PW91. 


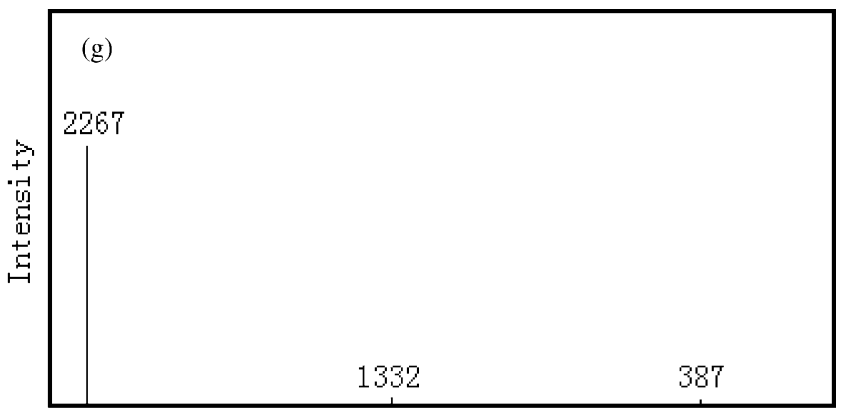

Wave Number ( $1 /$ cm)

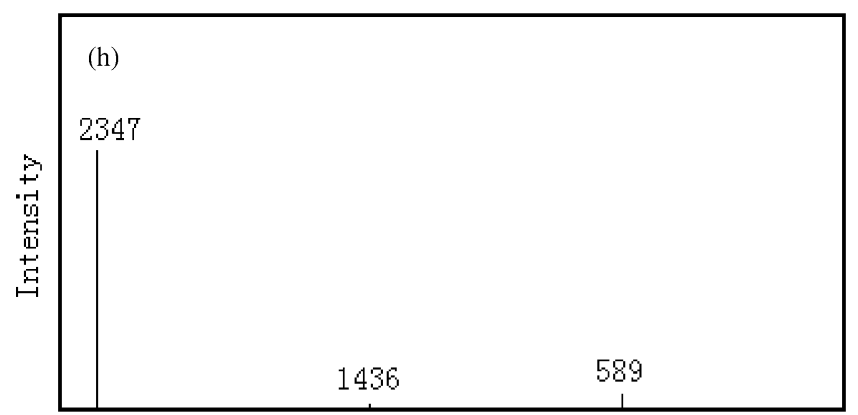

Wave Number $(1 / \mathrm{cm})$

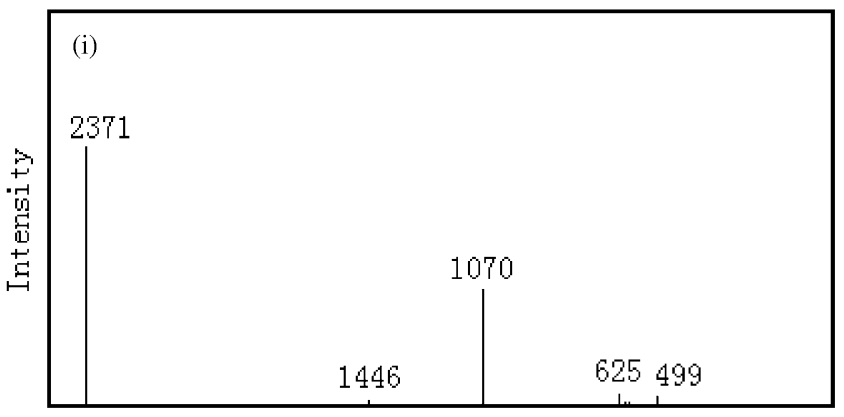

Wave Number $(1 / \mathrm{cm})$

Fig. 5. Calculated spectra of models $g, h$ and $i$ with the spectra simulated by the methods B3PW91.

at room temperature. With increased temperature, these two peaks decreased promptly, i.e. the NCO species is very active in the catalyst surface.

The assignment of the NCO stretching fundamentals for the NCO intermediates can be made based on the DFT calculation. From the experimental FT-IR spectra (see Fig. 7), the NCO antisymmetric stretching mode for the intermediates containing the group $(-\mathrm{Ag}-\mathrm{NCO})$ is clearly observed as a strong absorbance at $2212 \mathrm{~cm}^{-1}$; one for the intermediate containing the group $(-\mathrm{Al}-\mathrm{NCO})$ is clearly observed as a strong absorbance at $2237 \mathrm{~cm}^{-1}$. Because of the weak intensity, symmetric stretching mode for the surface structure containing the group $(-\mathrm{Ag}-\mathrm{NCO})$ or the group $(-\mathrm{Al}-\mathrm{NCO})$ has not be observed in the experimental FT-IR spectra. This point has been proved by the DFT calculation.

In the case of the calculated models (a-e), the calculated NCO antisymmetric stretching modes of the models (a-e) containing the group (-Ag-NCO) are 2333, 2264, 2321,

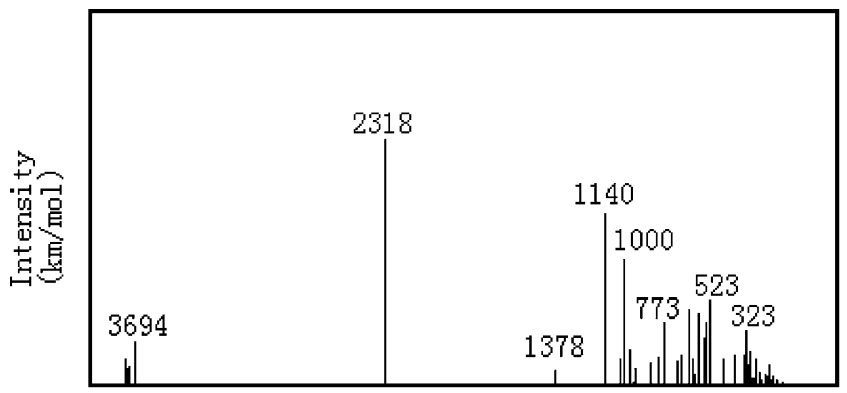

Wave Number $(1 / \mathrm{cm})$

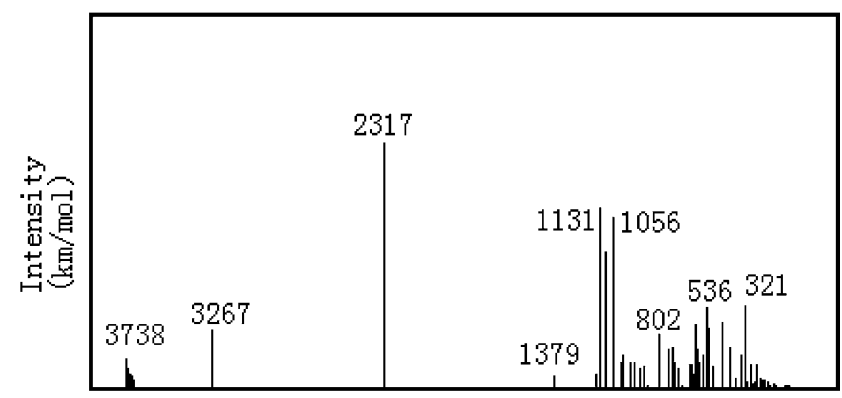

Wave Number $(1 / \mathrm{cm})$

Fig. 6. Calculated spectra of models $\mathrm{j}, \mathrm{k}$ with the spectra simulated by the methods B3PW91.

2308 and $2215 \mathrm{~cm}^{-1}$, respectively (Figs. 3 and 4). For the same experimental frequency $2212 \mathrm{~cm}^{-1}$, overestimation of experimental frequency values is on average about $5.47 \%$ for model (a), $2.35 \%$ for model (b), $4.93 \%$ for model (c), $4.34 \%$ for model (d) and $0.14 \%$ for model (e). The calculated spectrum of model (e) at $2215 \mathrm{~cm}^{-1}$ with $967 \mathrm{~km} \mathrm{~mol}^{-1}$ intensity is similar to the experimental spectrum at $2212 \mathrm{~cm}^{-1}$ with strong absorbance. The expressed frequency at $2215 \mathrm{~cm}^{-1}$ for the model (e), containing the group (-Ag-NCO) in Fig. 4, is a relatively good match of the most intense bands at $2212 \mathrm{~cm}^{-1}$ in the experimental spectrum (see Fig. 7).

In the case of the calculated models $(\mathrm{f}-\mathrm{k})$, the calculated $\mathrm{NCO}$ antisymmetric stretching modes $\nu_{\mathrm{a}}(\mathrm{NCO})$ containing the group (-Al-NCO) are 2336, 2267, 2347, 2371, 2378 and $2317 \mathrm{~cm}^{-1}$, respectively (Figs. 4 and 6). For the same experimental frequency $2237 \mathrm{~cm}^{-1}$, overestimation of experimental frequency values is on average about $4.43 \%$ for model (f), $1.34 \%$ for model (g), $4.92 \%$ for model (h), $5.99 \%$ for model (i), $6.30 \%$ for model (j) and $3.58 \%$ for model (k). The $v_{\mathrm{a}}(\mathrm{NCO})$ frequency of model $(\mathrm{g})$ calculated at $2267 \mathrm{~cm}^{-1}$ with $1228 \mathrm{~km} \mathrm{~mol}^{-1}$ intensity is only $30 \mathrm{~cm}^{-1}$ higher than the experimental spectrum at $2237 \mathrm{~cm}^{-1}$ with strong transmittance within $1.34 \%$ error. The expressed frequency at $2267 \mathrm{~cm}^{-1}$ for model ( $\mathrm{g}$ ) containing the group (-Al-NCO) in Fig. 5 is a relatively good match of the most intense bands at $2237 \mathrm{~cm}^{-1}$ in the experimental spectrum (Fig. 7).

Comparison with the experimental data shows that the spectra of model (e) and (g) simulated by DFT-B3PW91 evidently best match the experimental counterparts for the overwhelming majority of the calculated models $(\mathrm{a}-\mathrm{k})$ considered in the present study. 


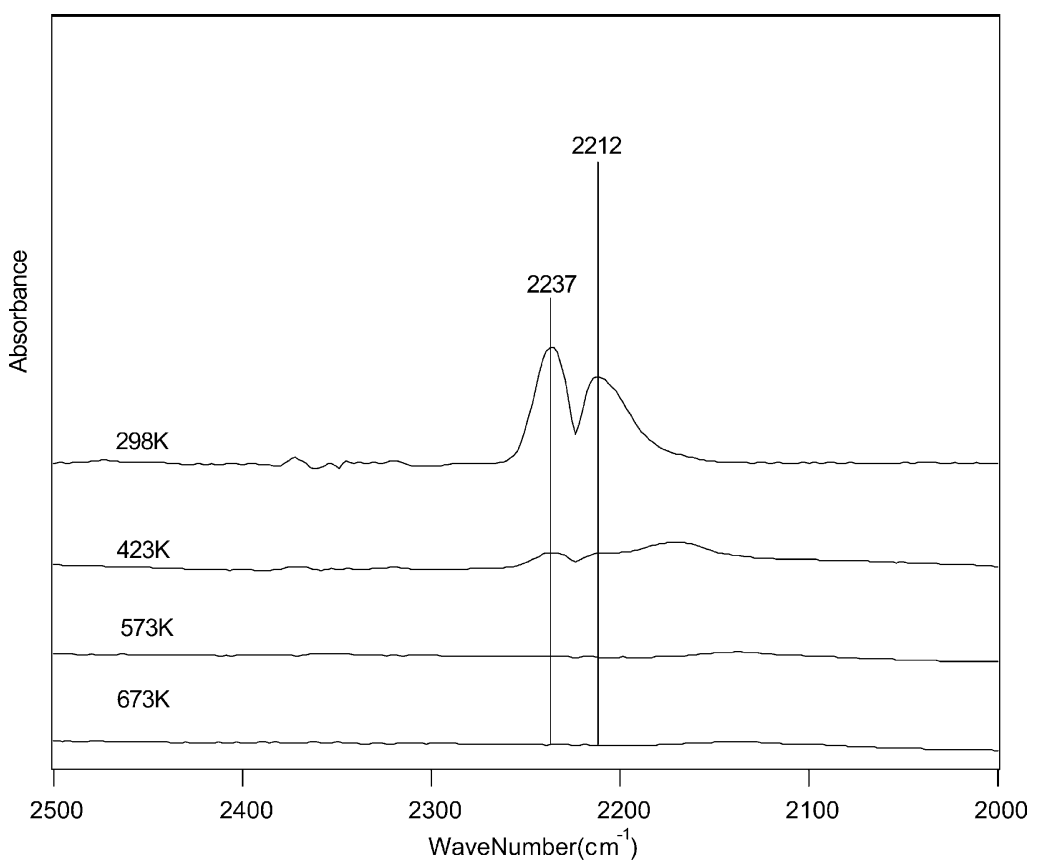

Fig. 7. In situ DRIFTS spectra of NCO adsorbed species in steady states on $\mathrm{Ag} / \mathrm{Al}_{2} \mathrm{O}_{3}$ in the flow of He at: (a) $298 \mathrm{~K}$; (b) $523 \mathrm{~K}$; (c) $573 \mathrm{~K}$; (d) $673 \mathrm{~K}$. Conditions: $\mathrm{CH}_{3} \mathrm{NO}_{2}$ adsorbed on catalyst surface at room temperature for $5 \mathrm{~min}$ and the spectra were measured in the flow of He gas.

\section{Conclusions}

Simulating infrared spectra with DFT, quantum mechanical method can be considered as an advantageous auxiliary tool for the FT-IR identification of unambiguous compounds. The calculations show clearly that the calculated IR spectra for models (e) and (g) are in good agreement with the corresponding experimental spectra. We conclude that models (e) and $(\mathrm{g})$ are the best models for the NCO intermediates containing the groups $-\mathrm{Ag}-\mathrm{NCO}$ and $-\mathrm{Al}-\mathrm{NCO}$, respectively.

\section{Acknowledgements}

This work was financially supported by the Chinese Academy of Sciences Program for Attracting Overseas Professionals and the State Hi-Tech Research and Development Project of the Ministry of Science and Technology, People's Republic of China (Grant 2003AA643040).

\section{References}

[1] V.A. Basiuk, R. Navarro-Gonzalez, E.V. Basiuk, J. Anal. Appl. Pyrolysis 45 (1998) 89.

[2] S. Sommer, R. Kamps, S. Schumm, K.F. Kleinermanns, Anal. Chem. 69 (1997) 1113.

[3] C.J.Pouchert, The Aldrich Library of FT-IR Spectra, first ed., vol. 3, Vapor Phase, Aldrich Chemical Company, Milwaukee, 1989, pp. 779-C, 788-B, 790-A.

[4] V.A. Basiuk, R. Navarro-Gonzalez, J. Chromatogr. A 776 (1997) 225 .
[5] M. Iwamoto, H. Yahiro, S. Shundo, Y. Yu-u, N. Mizuno, Appl. Catal. 69 (1991) 15.

[6] S.-C. Shen, S. Kawi, J. Catal. 213 (2003) 241-250.

[7] H. Permana, K. Simon Ng, C.H. Peden, S.J. Schmieg, D.K. Lambert, D.N. Belton, J. Catal. 164 (1996) 194.

[8] G. Srinivas, S.S.C. Chuang, S. Debnath, J. Catal. 148 (1994) 748.

[9] T. Tanaka, T. Okuhara, M. Misono, Appl. Catal. B 4 (1994) L1.

[10] S. Sumiya, H. He, A. Abe, N. Takezawa, K. Yoshida, J. Chem. Soc. Faraday Trans. 94 (1998) 2217.

[11] R. Burch, J.P. Breen, F.C. Meunier, Appl. Catal. B: Environ. 39 (2002) 283-303.

[12] Y.B. Yu, H. He, Q.C. Feng, J. Phys. Chem. 107 (2003) 13090-13092.

[13] S. Sumiya, M. Saito, H. He, Q-C. Feng, N. Takezawa, Catal. Lett. 50 (1998) 87.

[14] S. Kameoka, Y. Ukisu, T. Miyadera, Phys. Chem. Chem. Phys. 2 (2000) 367

[15] J.R. Durig, L. Zhou, T.K. Gouney, G.A. Guirgis, Spectrochim. Acta 53A (1997) 1581.

[16] S. Kameoka, T. Chafik, Y. Ukisu, T. Miyadera, Catal. Lett. 55 (1998) 211.

[17] M.J. Frisch, G.W. Trucks, H.B. Schlegel, G.E. Scuseria, M.A. Robb, J.R. Cheeseman, V.G. Zakrzewski, J.A. Montgomery, R.E. Stratmann, J.C. Burant, S. Dapprich, J.M. Millam, A.D. Daniels, K.N. Kudin, M.C. Strain, O. Frakas, J. Tomasi, V. Barone, M. Cossi, R. Cammi, B. Mennucci, C. Pomelli, C. Adamo, S. Clifford, J. Ochterski, G.A. Petersson, P.Y. Ayala, Q. Cui, K. Morokuma, D.K. Malick, A.D. Rabuck, K. Raghavachari, J.B. Foresman, J. Cioslowski, J.V. Ortiz, A.G. Baboul, B.B. Stefanov, G. Liu, A. Liashenko, P. Piskorz, I. Komaromi, R. Gomperts, R.L. Martin, D.T. Fox, T. Keith, M.A AI-Laham, C.Y. Peng, A. Nanayakkara, C. Gonzalez, M. Challacombe, P.M.W. Gill, B.G. Johnso, W. Chen, W. Wong, J.L. Andress, M. Head-Gordon, E.S. Replogle, J.A. Pople, Gaussian Inc., Pittsburgh, PA (1998).

[18] J.R. Durig, L. Zhou, T.K. Gounev, G.A. Guirgis, Spectrochim. Acta 53A (1997) 1581. 